\title{
Removal of Chromium (VI) from Aqueous Solution using Charred Pomegranate Waste
}

\author{
Rajendra Prasad Gautam and Megh Raj Pokhrel* \\ Central Department of Chemistry, Tribhuvan University, Kirtipur, Kathmandu, Nepal \\ E-mail:meghraj11@hotmail.com
}

\begin{abstract}
Removal of Cr(VI) from aqueous solution was studied using charred pomegranate fruit waste [CPW] as a new low cost biosorbent under batch method at room temperature. Its efficiency for removal of $\mathrm{Cr}(\mathrm{VI})$ was compared with raw pomegranate fruit waste[RPW]. Various sorption parameters such as contact time, initial concentration of $\mathrm{Cr}(\mathrm{VI})$ ion and effect of $\mathrm{pH}$ on the adsorption capacity of the biosorbent were studied. The adsorbent was effective for quantitative removal of $\mathrm{Cr}(\mathrm{VI})$ ions in highly acidic condition $(\mathrm{pH}=1)$ and equilibrium has been achieved in 2 hours. The adsorption isotherm data were fitted to Langmuir and Freundlich adsorption isotherm models and the model parameters were evaluated. Spectrophotometric method using diphenylcarbazide as a complexing reagent was used to analyze the chromium content in synthetic samples and the landfill site effluent collected from Kuleshwor, Kathmandu, Nepal.
\end{abstract}

Keywords: Chromium, diphenylcarbazide, pomegranate, adsorption.

\section{Introduction}

Heavy metals are toxic pollutants released into the environment as a result of different human activities. Rapid industrialization and increase in human population is responsible for the inclusion of heavy metals into the aquatic as well as in terrestrial environments ${ }^{1}$. Heavy metals such as mercury, lead, cadmium, copper, chromium and nickel are toxic even in extremely minute quantities on human health and to the flora and fauna receiving water. Heavy metals are not biodegradable and accumulate in living organisms, causing various diseases and disorders ${ }^{2}$. Chromium exists in two stable oxidation states $\mathrm{Cr}(\mathrm{III})$ and $\mathrm{Cr}(\mathrm{VI})$. Although $\mathrm{Cr}(\mathrm{III})$ is considered as an essential trace element, $\mathrm{Cr}(\mathrm{VI})$ is carcinogenic, toxic and mutagenic. $\mathrm{Cr}(\mathrm{VI})$ is water soluble and easily enters the living cells. Therefore, removal of hexavalent chromium from waste water is of particular concern ${ }^{3}$.

Adsorption is a well-established and powerful technique for waste water treatment. It has advantages over the other methods because of its simple design with a sludge free environment and can involve low investment in terms of both initial cost and require for its operation ${ }^{4}$. Activated carbon has been the most widely used adsorbent for removal of heavy metals from the concentrate and dilute effluents. Activated carbons with their large surface area, micro porous character and chemical nature of their surface area have made them potential adsorbent for the removal of heavy metals from waste water. This process has not been used by small and medium scale industries because of its high manufacturing cost. For this reason, the use of low cost materials as adsorbent for metal ion removal from the waste water has been highlighted however efforts have been contributed to develop new adsorbent and improve the existing

\footnotetext{
* Corresponding author
} 
adsorbents to have an alternative to activated carbon. These materials range from industrial waste products such as rubber tyres, agricultural waste products and bio-products ${ }^{5}$.

In Nepal, plenty of biomaterials like rice husk, maize barn, apple waste, pomegranate waste, orange waste and banana bark are easily available as the waste materials. Pomegranate (Punica grantum) is one of the popular fruit. It is mainly grown in Hilly region of Nepal. The pomegranate fruit waste is available in large amount in the juice vending centers. The waste is just thrown away and becomes a part of pollutants. Therefore, it is quite suitable to use it as an adsorbent rather than wasting it and creating problem of its disposal. The charred pomegranate waste is an excellent and potential adsorbent for the adsorption of $\mathrm{Cr}(\mathrm{VI})$ contaminated industrial effluent ${ }^{6}$. Hexavalent chromium, $\mathrm{Cr}(\mathrm{VI})$ exists in the aqueous solution as oxy anions such as chromate $\left(\mathrm{CrO}_{4}^{-}\right)$, dichromate $\left(\mathrm{Cr}_{2} \mathrm{O}_{7}^{-}\right)$, acid chromates $\left(\mathrm{HCrO}_{4}^{-}\right)$, and $\left(\mathrm{HCrO}_{7}^{-}\right)$forms ${ }^{7}$.

The objective of the present study is to evaluate the capacity of chemically modified pomegranate waste to remove chromium (VI) from aqueous solutions using batch adsorption process.

\section{Experimental Methods}

\section{Preparation of adsorbents}

Pomegranate waste used in this research work was collected from a fruit-seller at Kirtipur, Kathmandu. The waste was washed, cleaned and then dried in sunlight for a week. The fully dried waste was powdered in grain crusher. The powered waste was again dried in sunlight for 3 days and crushed very finely in the grain crusher. The finely powdered raw adsorbent was packed in an air tight bottle.

When raw pomegranate waste $[R P W]$ is treated with concentrated sulphuric acid at laboratory temperature, it produces an adsorbent having high surface area and high degree of micro porosity. For the process of chemical modification, the RPW was mixed in 1:2 (W/V) ratios with concentrated $\mathrm{H}_{2} \mathrm{SO}_{4}$ and allowed to soak for 24 hours at room temperature to ensure complete reaction. The excess of acid was removed by washing it with distilled water until the $\mathrm{pH}$ of the filtrate was neutral. Then, it was dried at $100{ }^{\circ} \mathrm{C}$ for 6 hours in hot air oven and sieved to $212 \mu \mathrm{m}$ particle size.

\section{Preparation of chromium solution and analysis}

A stock solution of $\mathrm{Cr}(\mathrm{VI})(500 \mathrm{mg} / \mathrm{L})$ was obtained by dissolving $1.4144 \mathrm{~g}$ of potassium dichromate ( in $1 \mathrm{~L}$ of distilled water, and the solution was used for further experimental solution preparation. The $\mathrm{pH}$ values were adjusted with $1 \mathrm{M} \mathrm{HNO}_{3}$ or $1 \mathrm{M} \mathrm{NaOH}$. The $\mathrm{Cr}(\mathrm{VI})$ content in the sorption solutions was determined by WPA Linton Cambridge UK Spectrophotometer type S104 No. 385 at $\lambda_{\max } 540 \mathrm{~nm}$ by diphenylcarbazide method. For comparison of the results, the chromium content in a waste water sample was also determined by atomic absorption spectrometer (type Solar M. series No. UAA 09901, Thermo Elemental UK).

\section{Batch adsorption studies}

Batch adsorption studies were carried for both adsorbents using $125 \mathrm{~mL}$ stoppered bottles containing $25 \mathrm{~mL}$ of the test solutions at the desired initial chromium concentration and $\mathrm{pH}$. The required amount $(25 \mathrm{mg})$ of adsorbent was then added and the flask contents were shaken for the required contact time at room temperature using mechanical shaker. The contents of the flask were filtered immediately through filter paper and filtrate was analyzed for final chromium concentration using spectrophotometer. The amount of adsorbed chromium was calculated from the decrease in the chromium concentrations. From $\mathrm{Cr}(\mathrm{VI})$ concentrations measured before and after the adsorption $\left(\mathrm{C}_{\mathrm{o}}\right.$ and $\mathrm{C}_{\mathrm{e}}$, respectively) and dry weight of adsorbent (W), as well as volume of aqueous solution (V), the amount of adsorption of $\mathrm{Cr}(\mathrm{VI})$ (q) was calculated according to the equation 


$$
\mathrm{q}=\frac{\mathrm{C}_{\mathrm{o}}-\mathrm{C}_{\mathrm{e}}}{\mathrm{W}} \times \mathrm{V}(\mathrm{mg} / \mathrm{g})
$$

The removal percentage ( $\mathrm{R} \%$ ) was calculated according to the equation

$$
\mathrm{R}(\%)=\frac{\mathrm{C}_{\mathrm{o}}-\mathrm{C}_{\mathrm{e}}}{\mathrm{C}_{\mathrm{o}}} \times 100
$$

Batch pH studies were conducted by shaking $25 \mathrm{~mL}$ of $20 \mathrm{mg} / \mathrm{L} \mathrm{Cr}(\mathrm{VI})$ solution with $25 \mathrm{mg}$ of adsorbents (raw \& charred) for 24 hours, so as to ensure the attainment of equilibrium over a wide range of initial $\mathrm{pH}$ values from 1 to 6 .

Equilibrium times for the adsorption of $\mathrm{Cr}(\mathrm{VI})$ onto raw and charred pomegranate wastes were studied at optimum $\mathrm{pH}$ value at room temperature. $25 \mathrm{~mL}$ of solution $(20 \mathrm{mg} / \mathrm{L})$ was taken in $125 \mathrm{~mL}$ stoppered bottles with $25 \mathrm{mg}$ of adsorbents and was shaken in a mechanical shaker for 10, 20, 30, 40, 50, $60,70,80,90,100,110,120,150$ minutes, 3, 4, 5, 6, and 12 hours. The metal ion concentration before and after adsorption were determined by spectrophotometric method.

To evaluate the adsorption isotherms, the batch-wise adsorption test was carried out for $\mathrm{Cr}(\mathrm{VI})$ in the concentration range of 10 to $500 \mathrm{mg} / \mathrm{L}$ at optimum $\mathrm{pH}(=1)$ values and contact time (24 hours) using the procedure described above. Equilibrium data, which are commonly known as adsorption isotherms, are basic requirements for the design of adsorption systems. Classical adsorption models (Langmuir and Freundlich) were used to describe the equilibrium between adsorbed $\mathrm{Cr}(\mathrm{VI})$ on the adsorbent and $\mathrm{Cr}(\mathrm{VI})$ in solution and to get information on the molecular interaction/adsorption mechanism between the adsorbent and $\mathrm{Cr}(\mathrm{VI})$.

\section{Analysis of water sample}

The water sample was collected from the contaminated landfill site located at Kuleshwor, Kathmandu, Nepal. The sample was collected in plastic bottles which were thoroughly cleaned by $8 \mathrm{M}$ nitric acid followed by repeated washing with distilled water and dried over night. After collecting sample, $1.5 \mathrm{ml}$ of concentrated nitric acid per liter of sample was added as preservative. The $\mathrm{pH}$ of the sample was maintained below 2 by adding dilute nitric acid and stored at room temperature.

The chromium content of sample solution was determined by atomic absorption spectrometer. For this analysis, $0.5 \mathrm{~mL}$ of concentrated nitric acid was added to $100 \mathrm{~mL}$ of sample solution and concentrated on a hot plate. The final volume was adjusted to $10 \mathrm{~mL}$ which was aspirated into atomic absorption spectrometer. The absorbance of the sample was measured and the concentration of chromium was determined with the help of calibration curve. Atomic absorption spectroscopic measurement was performed at Nepal Environment and Scientific Services, Thapathali, Kathmandu.

\section{Results and Discussion}

\section{Effect of pH}

The $\mathrm{pH}$ of the aqueous solution is an important parameter in the removal of metal ion by adsorption. Figure 1 shows the effect of $\mathrm{pH}$ on the adsorption of $\mathrm{Cr}(\mathrm{VI})$ onto charred and raw pomegranate wastes at an initial concentration of $20 \mathrm{mg} / \mathrm{L}$ at room temperature. When the initial $\mathrm{pH}$ of the solution was increased from 1.0 to 6.0 , the percentage removal decreased from $91.18 \%$ to $26.47 \%$ in case of charred pomegranate waste and $54.55 \%$ to $5.08 \%$ in case of raw material. The maximum adsorption of $\mathrm{Cr}(\mathrm{VI})$ occurred at $\mathrm{pH}$ 1. It is well known that the dominant form of $\mathrm{Cr}(\mathrm{VI})$ at this $\mathrm{pH}$ is $\mathrm{HCrO}_{4}^{-}$. Increasing the $\mathrm{pH}$ will shift the concentration of $\mathrm{HCrO}_{4}{ }^{-}$to the other forms, $\mathrm{CrO}_{4}{ }^{2-}$ and $\mathrm{Cr}_{2} \mathrm{O}_{7}{ }^{2-}$. It can be concluded that 


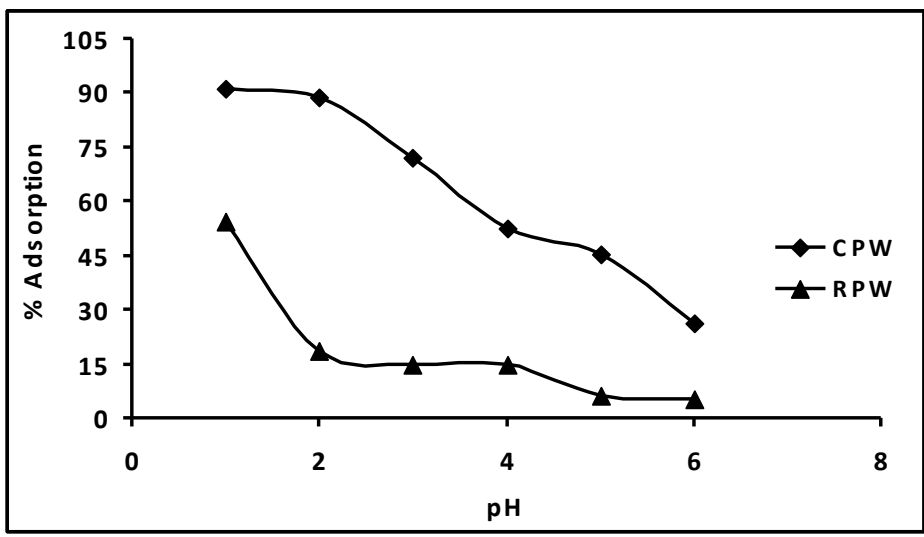

Figure 1: Effect of pH on adsorption of $C r(V I)$ onto $C P W$ and $R P W$

the active form of $\mathrm{Cr}(\mathrm{VI})$ that can be adsorbed by both adsorbents chosen in this study is $\mathrm{HCrO}_{4}$ Moreover, the surface of $\mathrm{CPW}$ becomes highly protonated under acidic conditions that favoured the adsorption of $\mathrm{Cr}(\mathrm{VI})$ in the anionic form ${ }^{8}$. The increase in $\mathrm{pH}$ value caused a decrease in protonation of the surface, which led to a decrease in the net positive surface potential of adsorbent. This decreased the electrostatic forces between adsorbent and adsorbate, leading to reduced adsorption capacity ${ }^{9}$.

\section{Effect of initial concentration of metal ion: Adsorption isotherms}

Figure 2 shows the removal of $\mathrm{Cr}(\mathrm{VI})$ by adsorption onto RPW and CPW. The adsorption increases from lower concentration to higher concentration range and attained equilibrium.

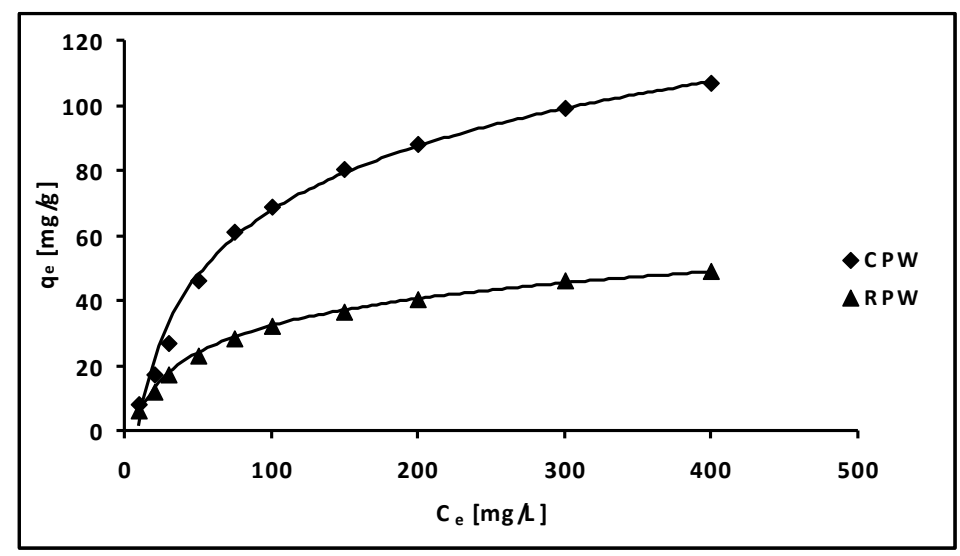

Figure 2: Effect of initial concentration of $C r(V I)$ on the adsorption of $C r(V I)$ onto $C P W$ and $R P W$

As the initial concentration of $\mathrm{Cr}(\mathrm{VI})$ was increased from $10 \mathrm{mg} / \mathrm{L}$ to $400 \mathrm{mg} / \mathrm{L}$, the amount adsorbed was increased from $8.83 \mathrm{mg} / \mathrm{g}$ to $107 \mathrm{mg} / \mathrm{g}$ for CPW \& $6.10 \mathrm{mg} / \mathrm{gm}$ to $49 \mathrm{mg} / \mathrm{g}$ for RPW respectively. The $\mathrm{pH}$ of the system was adjusted to 1 and the agitation was done for 12 hours. The amount adsorbed was increased with an increase in concentration of adsorbate. It means that the adsorption is highly dependent on initial concentration of metal ions. The percentage removal of $\mathrm{Cr}(\mathrm{VI})$ decreases with an increase in initial $\mathrm{Cr}(\mathrm{VI})$ concentration. It may be due to an increase in the number of $\mathrm{Cr}(\mathrm{VI})$ ions for the fixed 
amounts of CPW and RPW. Uptake of $\mathrm{Cr}(\mathrm{VI})$ increased with increasing the initial metal concentration tending to saturation at higher concentrations ${ }^{11}$.

It is because of the fact that at lower concentration, the ratio of the initial number of metal ion to the available surface area is low. From this observation, it is concluded that when the material is modified, the amount adsorbed has increased.

The main objective of isotherm study is to evaluate the capacity of the modified bioadsorbents to sequester $\mathrm{Cr}$ (VI) from an aqueous solution. It was done by characterizing the equilibrium state of the CPW and RPW that have been allowed to react with aqueous solution of $\mathrm{Cr}(\mathrm{VI})$. The isotherm studies were performed using various initial concentrations of $\mathrm{Cr}(\mathrm{VI})(10 \mathrm{mg} / \mathrm{L}$ to $400 \mathrm{mg} / \mathrm{L})$ to which a constant weight $(25 \mathrm{mg}$ ) of adsorbent and a volume of $25 \mathrm{~mL}$ of $\mathrm{Cr}(\mathrm{VI})$ at optimum $\mathrm{pH}$ was applied in $125 \mathrm{~mL}$ stoppered bottles. The Langmuir and Freundlich models were used to analyze adsorption data.

The Langmuir equation applied for adsorption equilibrium is as follows ${ }^{10}$ :

$$
\mathrm{C}_{\mathrm{e}} / \mathrm{q}_{\mathrm{e}}=1 / \mathrm{q}_{\mathrm{m}} \mathrm{b}+\mathrm{C}_{\mathrm{e}} / \mathrm{q}_{\mathrm{m}}
$$

Where $\mathrm{C}_{\mathrm{e}}$ is the equilibrium concentration $(\mathrm{mg} / \mathrm{L}), \mathrm{q}_{\mathrm{e}}$ the amount adsorbed under equilibrium $(\mathrm{mg} / \mathrm{L}), \mathrm{q}_{\mathrm{m}}$ the theoretical maximum adsorption capacity corresponding to complete monolayer coverage ( $\mathrm{mg} / \mathrm{g}$ ), and $\mathrm{b}(1 / \mathrm{mg})$ is a Langmuir constant related to the enthalpy of adsorption. $\mathrm{q}_{\mathrm{m}}$ and $\mathrm{b}$ are determined from the slope and intercept of the plot of $\mathrm{C}_{\mathrm{e}} / \mathrm{q}_{\mathrm{e}}$ versus $\mathrm{C}_{\mathrm{e}}$. The value of $\mathrm{R}^{2}$ can be regarded as a measure of the quality of fit of experimental data on isotherm models. The adsorption data could be described well by Langmuir model for $\mathrm{Cr}(\mathrm{VI})\left(\mathrm{R}^{2} \geq 0.99\right)$. The Langmuir model assumes that the adsorption of the metal ions occurs on a homogenous surface by monolayer without any interaction between the adsorbate and adsorbent.

The Freundlich isotherm assumes that the uptakes of metal ions occur on a heterogenous surface by multilayer adsorption and that the amount of adsorbate adsorbed increases infinitely with an increase in concentration. It can be expressed in the linear form as follows ${ }^{11}$ :

$$
\log \mathrm{q}_{\mathrm{e}}=\log \mathrm{K}_{\mathrm{F}}+1 / \mathrm{n} \log \mathrm{C}_{\mathrm{e}}
$$

where $\mathrm{K}_{\mathrm{F}}\left(\mathrm{Lmg}^{-1}\right)$ and $\mathrm{n}$ are constants which are considered to be the relative indicators of adsorption capacity and adsorption intensity. A plot of $\log q_{e} v s \log C_{e}$ gives a linear trace with a slope of $1 / n$ and intercept of $\log \mathrm{K}_{\mathrm{F}}$.

Adsorption of $\mathrm{Cr}(\mathrm{VI})$ onto $\mathrm{CPW}$ and RPW gives the linear relationship with Langmuir and Freundlich isotherms which are shown in Figure 3 and Figure 4. Langmuir and Freundlich parameters are determined from the slope and intercept of their respective plots. Their values are presented in Table 1 . The value of Langmuir equilibrium parameter lies between 0 and 1 indicating that equilibrium data fits well with Langmuir adsorption isotherm.

Table 1: Langmuir and Freundlich parameters for the adsorption of Cr(VI) onto charred and raw pomegranate waste

\begin{tabular}{|l|l|l|l|l|l|l|l|}
\hline Adsorbents & $\begin{array}{l}\mathrm{q}_{\mathrm{m}} \text { exp. } \\
(\mathrm{mg} / \mathrm{g})\end{array}$ & \multicolumn{2}{l|}{ Langmuir Isotherm } & \multicolumn{2}{l|}{ Freundlich Isotherm } \\
\cline { 3 - 8 } & & $\begin{array}{l}\mathrm{q}_{\mathrm{m}} \\
(\mathrm{mg} / \mathrm{g})\end{array}$ & $\begin{array}{l}\mathrm{b} \\
(\mathrm{L} / \mathrm{mg})\end{array}$ & $\mathrm{R}^{2}$ & $\mathrm{~K}(\mathrm{mg} / \mathrm{g})$ & $1 / \mathrm{n}$ & $\mathrm{R}^{2}$ \\
\hline $\mathrm{CPW}$ & 107 & 107.53 & 0.081 & 0.993 & 17.93 & 0.34 & 0.8159 \\
\hline $\mathrm{RPW}$ & 49 & 52.36 & 0.029 & 0.994 & 5.039 & 0.41 & 0.9364 \\
\hline
\end{tabular}




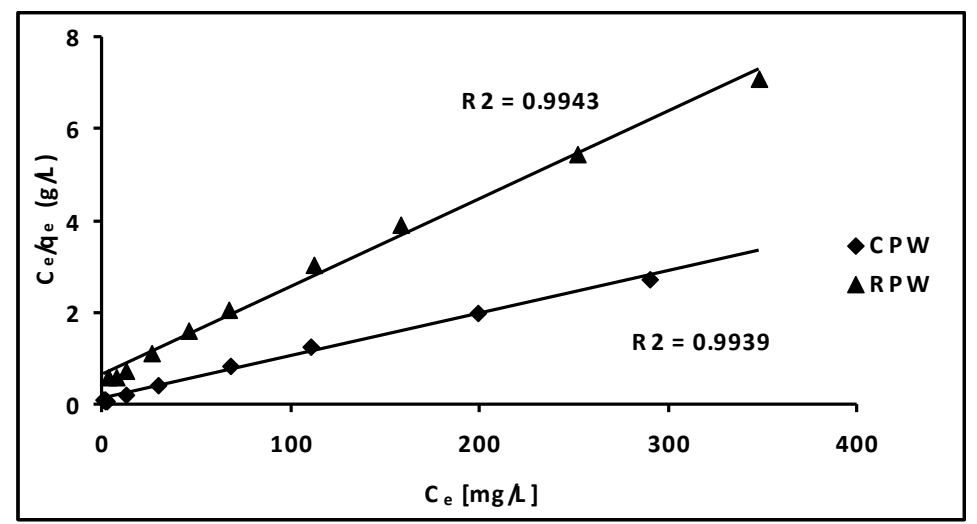

Figure 3: Langmuir adsorption isotherm plot for adsorption of $C r(V I)$ onto $C P W$ and $R P W$.

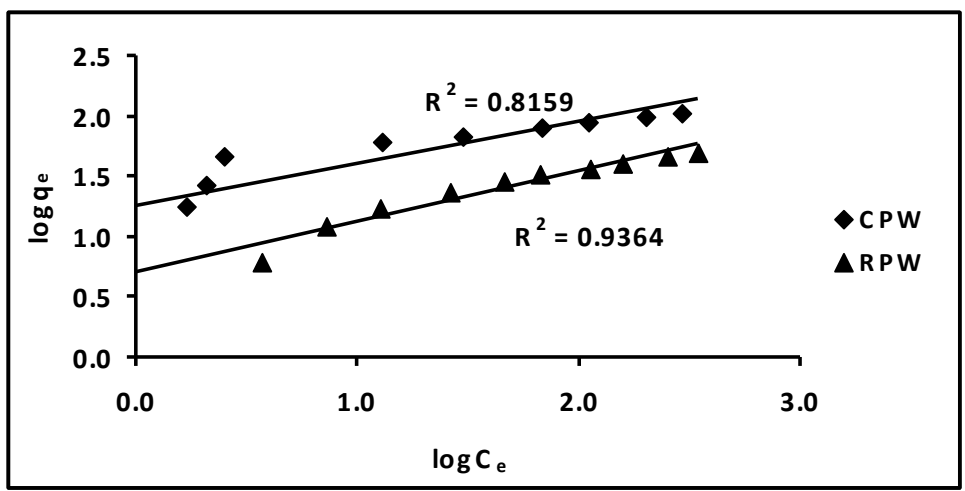

Figure 4: Freundlich adsorption isotherm plot for adsorption of $\mathrm{Cr}(\mathrm{VI})$ onto $C P W$ and $R P W$

On the other hand, Freundlich adsorption isotherm of CPW and RPW indicated that the equilibrium data fits with Freundlich adsorption isotherm. The value of 1/n lies between $0-1$ indicating favorable adsorption.

However, the correlation coefficient value for Langmuir isotherm is found to be greater than that of Freundlich plot. The value of the correlation coefficient, $\mathrm{R}^{2}$, obtained for Freundlich model gave a poorer fit to the experimental data than the Langmuir isotherm model. So the adsorption process revealed to follow Langmuir isotherm model.

\section{Effect of contact time}

Figure 5 shows the adsorption of $\mathrm{Cr}(\mathrm{VI})$ onto RPW and CPW from 10 minutes to 12 hours. Adsorption of chromium onto CPW and RPW was found to be constant after 150 minutes and 120 minutes respectively. The initial rapid rate of adsorption was may be due to the availability of the positively charged surface of the adsorbent for anionic $\mathrm{Cr}(\mathrm{VI})$ species present in solution. The later slow adsorption rate was may be due to the electrostatic hindrance caused by already adsorbed negatively charged adsorbate species and slow pore diffusion of the ions ${ }^{12}$. The sorption capacity decreases with time due to decrease in active sites of the adsorbent and after saturation sorption becomes constant. 


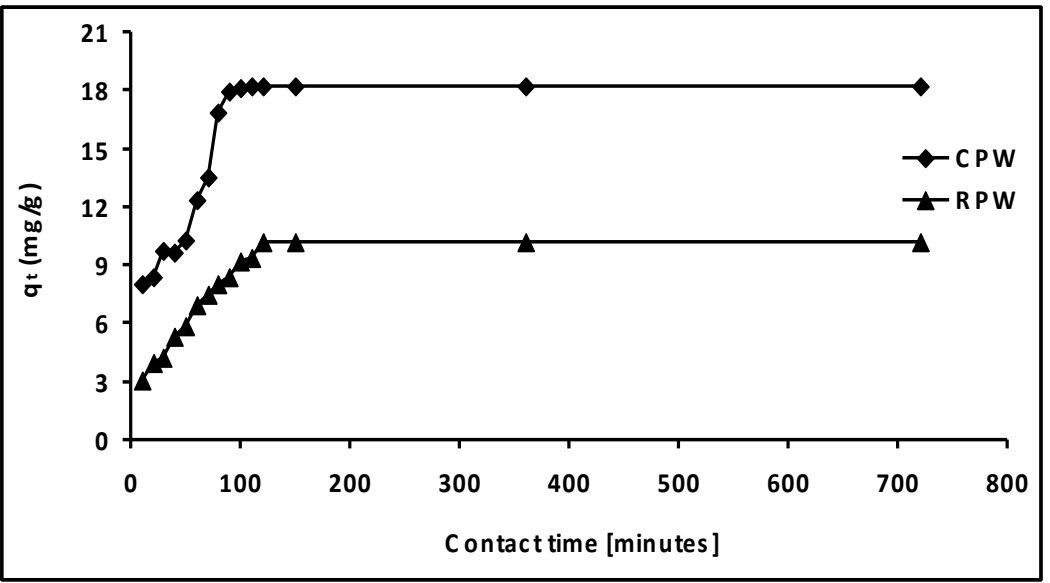

Figure 5: Effect of contact time on adsorption of $C r(V I)$ onto $C P W$ and $R P W$

\section{Analysis of water sample}

The water sample collected from contaminated landfill site of Kuleshwor, Kathmandu, Nepal was analyzed for chromium content by Spectrophotometric and Atomic Absorption Spectrometric methods. The sample was then subjected to adsorption with charred pomegranate waste. The results of the analysis are presented in the Table 2 and Table 3.

Table 2: Spectrophotometric Analysis of water sample

\begin{tabular}{|l|l|l|l|}
\hline Sampling site & $\begin{array}{l}\text { Initial concentration } \\
\left(\mathrm{C}_{\mathrm{i}}\right) \mathrm{mg} / \mathrm{L}\end{array}$ & $\begin{array}{l}\text { Equillibrium } \\
\text { concentration }\left(\mathrm{C}_{\mathrm{e}}\right) \\
\mathrm{mg} / \mathrm{L}\end{array}$ & \% Adsorption \\
\hline Kuleshwor, Kathmandu & 1.4 & 0.5 & $64.2 \%$ \\
\hline
\end{tabular}

Table3: Analysis of water sample by AAS

\begin{tabular}{|l|l|l|l|}
\hline Sampling site & $\begin{array}{l}\text { Initial } \\
\text { concentration }\left(\mathrm{C}_{\mathrm{i}}\right) \\
\mathrm{mg} / \mathrm{L}\end{array}$ & $\begin{array}{l}\text { Equillibrium } \\
\text { concentration }\left(\mathrm{C}_{\mathrm{e}}\right) \\
\mathrm{mg} / \mathrm{L}\end{array}$ & \% Adsorption \\
\hline Kuleshwor, Kathmandu & 1.22 & 0.36 & $70.5 \%$ \\
\hline
\end{tabular}

Table 2 and Table 3 show that 64\% chromium removal was achieved in natural sample by spectrophotometric method and 70.5\% chromium removal was achieved in natural sample by AAS method. Since AAS is more accurate method than spectrophotometric method so that the percentage removal of chromium is high in AAS method. Complete chromium removal was not achieved due to the competitive adsorption of chromium and the other metal ions present in the water sample. 


\section{Conclusions}

Pomegranate fruit waste product is converted into a carbonaceous adsorbent after treatment with concentrated sulphuric acid in a ratio of 1:2(W/V) and then it was used for removal of chromium ions from aqueous solutions.

The adsorption of $\mathrm{Cr}(\mathrm{VI})$ was found to be strongly dependent upon $\mathrm{pH}$ of the solution, initial concentration of the metal ion and contact time. The amount of $\mathrm{Cr}(\mathrm{VI})$ ion adsorbed decreased with increase in $\mathrm{pH}$ of the medium. The maximum adsorption capacity of $\mathrm{Cr}(\mathrm{VI})$ onto $\mathrm{CPW}$ was found to be $107 \mathrm{mg} / \mathrm{g}$ and that for RPW was $49 \mathrm{mg} / \mathrm{g}$ at their optimum $\mathrm{pH}$ 1. Langmuir and Freundlich adsorption isotherm models were tested to describe the adsorption of $\mathrm{Cr}(\mathrm{VI})$ on these adsorbents. It was inferred that Langmuir adsorption isotherm model was found to be more applicable than Freundlich adsorption isotherm model for the better description of the adsorption behavior of $\mathrm{Cr}(\mathrm{VI})$ ion. The equilibrium time for the adsorption of $\mathrm{Cr}(\mathrm{VI})$ onto $\mathrm{CPW}$ was 120 minutes whereas for raw pomegranate waste was 150 minutes respectively. On the basis of present studies, it can be concluded that the charred pomegranate waste (CPW) has a higher chromium adsorption capacities than raw material.

Water sample collected from Kuleshwor, Kathmandu, Nepal was analyzed for chromium content by spectrophotometric and atomic absorption spectrometric methods. The water sample was then subjected to adsorption with charred pomegranate waste. The removal of chromium from natural water sample was low as compared to synthetic sample. It may be due to the competitive adsorption of chromium with other metal ions present in the water sample.

\section{Acknowledgments}

The authors are very thankful to the Head of the Department, Central Department of Chemistry, Tribhuvan University, Kirtipur, Kathmandu, Nepal for providing the available research facilities to conduct this research work and to Mr. Alankar Kafle of Nepal Environment and Scientific Services, Thapathali, Kathmandu for his help to measure chromium content in water samples by AAS.

\section{References}

1. S. Arivoli, P. Martin Deva Prasath, M. Thenkuzhali, Elect. J. of Env. Agri. and Food Chem. 2007, 6, 2323-2340.

2. S.S. Baral, S. N. Das and P. Rath, J. Chem. Eng. 2002, 9, 167-172.

3. M. Chaib and F. Hattab, Int. J. Appl. Chem. 2007, 3, 107-118.

4. T. Virarghavan, Dronamrajum, J. Environ. Sci. Health, 1993, 28, 1261.

5. U. Kumar, Scientific Research and Essay, 2006, 12, 33-37.

6. N.A. Khan and H. Mohamad, Water and waste Water Asia, 200), 28, 87-94.

7. N. Ahalya , R.D. Kanamadi and T.V. Ram Chandram, Elec. J. Biotechnol, 2005, 8, 3.

8. C. Namasivayam and R.T. Yamuna, Chemosphere, 1995, 30, 561-578.

9. K. Selvi, S. Pattabhi and K. Kadirvelu, Bioresour Technol., 2001, 80, 87.

10. G. Crini, H.N. Peindy, F. Gimbert, Sep. Purif. Technol., 2007, 53, 97.

11. H.M.F. Freundlich, Phys. Chem., (Leipzig), 1906, 57A, 385-470.

12. P.K. Pandey, S.K. Sharma and S.S. Sambi, Int. J. Environ. Sci. Tech., 2010, 7, 395-404 